\title{
Propuesta organizativa para la materia "redes de computadoras" en un ambiente semipresencial.
}

\section{La materia "Redes de Computadoras" en modalidad semipresencial}

Ángel Luis Mercado Ollarzábal M.Sc. ${ }^{(1)}$

Manuel Linares Álvaro M. Sc. ${ }^{(2)}$

(1)Universidad de Granma, Bayamo, Cuba.

${ }^{(2)}$ Universidad de Granma, Bayamo, Cuba.

\section{Contacto: angelluis@udg.co.cu}

Receptado: 05/03/2015 Aceptado: 04/05/2015

\section{Resumen}

Actualmente, los programas de estudios que existen en varias carreras universitarias, como la de Ingeniero en Sistemas Informáticos, se caracterizan por emplear una modalidad semipresencial, y poseer una marcada disposición a la educación constructivista y significativa. Esta carrera posee en su plan de estudios asignaturas, como "Redes de Computadoras", que requieren de laboratorios correctamente equipados que no siempre están disponibles debido a los altos costos en el mercado y lo escasos que resultan los diferentes dispositivos que se emplean en las redes de ordenadores. En un ambiente que utilice cualquiera de las modalidades educativas antes mencionadas, esta situación se hace aún más crítica. El presente trabajo, se enmarca en la necesidad de dar soluciones a la situación anterior. La idea central es organizar los contenidos de la asignatura Redes de Computadoras, usando mapas conceptuales a los cuales estén asociados recursos multimedios tales como textos, imágenes, animaciones, y sobre todo, simulaciones de procesos o equipos propios de las redes de computadoras, y luego compartirlos en un servidor CMap, "visible" en la red Internet, de manera que permitan, en primera instancia, resolver las carencias señaladas y en general constituyan un soporte de apoyo a la enseñanza de la materia.

Palabras claves. Redes de computadoras, mapas conceptuales, enseñanza a distancia, routers, protocolo IP 
Rev. SINAPSIS, Vol. 6, Nº 1, Junio 2015

Organizational proposal for the subject "Computer Networks" in a part- time environment.

\begin{abstract}
Nowadays, the curricula that exist in various university courses, such as Computer Systems Engineering are characterized by employing a part time format, and possess a strong disposition to constructive and meaningful education. This career has in its plan of subjects studies as "Computer Networks", which require adequately equipped laboratories are not always available due to high costs in the market and few that are different devices used in networks of computers. In an environment that uses any of the aforementioned types of education, the situation becomes even more critical. This work is part of the need to provide solutions to the previous situation. The central idea is to organize the contents of the course Computer Networks, using conceptual maps which associated multimedia resources such as text, images, animations, and above all, process simulations or own teams of computer networks are, then share a "visible" on the Internet CMap server, so as to allow, in the first instance, to solve identified deficiencies.
\end{abstract}

Keywords: Computer networks, concept mapping, distance learning, routers, IP protocol

\title{
Introducción
}

La Universidad en Ecuador, se encuentra actualmente ante el reto de modificar sus modalidades y programas de estudio, en estos momentos se busca la manera de lograr un proceso docente sustentado en planes de estudio que se caracterizados por ser semipresenciales, marcadamente constructivistas y significativos, propiedades que desempeñarán un papel determinante en este proceso de renovación, las cuales también conducirían a una educación más inclusiva.

Con respecto a lo anteriormente planteado, Torres, Quezada y Germán sostenían en el año 2010 que Ecuador daba sus primeros pasos en la educación virtual y la aplicación de estas tecnologías se daba en las distintas modalidades y a diferentes niveles de la oferta académica, sin embargo, también exponían que a pesar de ser la tasa de crecimiento de los programas, lenta; ya se preveía contar con un incremento significativo de nuevos programas que utilizaban las TICs. Estos autores eran del criterio de que dentro de la oferta virtual de las universidades, la modalidad a distancia con componentes virtuales es la que contaba con mayores aceptaciones, y que eran los programas virtuales en preparación los que presentaban un potencial crecimiento. (Torres, Morocho, \& Germán, 2010). 
Rev. SINAPSIS, Vol. 6, Nº 1, Junio 2015

Los mencionados autores señalaban, como unas de las principales barreras para la educación virtual y el uso de las TICs en la enseñanza, el mal estado generalizado de las telecomunicaciones, la falta de calidad y los elevados precios de los servicios de acceso a internet en el país, sin embargo, en la actualidad, todas estas barreras están prácticamente superadas: es notorio el salto significativo que se ha experimentado, en las telecomunicaciones y sus servicios, el acceso a redes públicas se ha masificado, y los costos se han reducido considerablemente, además, el uso de las TICs es cada vez más generalizado.

En el Ecuador, a finales de 2008, la mayor cantidad de programas de pregrado se encontraban en la modalidad de estudios presenciales con componentes a distancia. (Torres et al., 2010)

Las carreras de perfil informático de la Universidad Laica "Eloy Alfaro" de Manabí, Extensión Chone (ULEAM-Chone), no constituyen una excepción de la situación descrita con anterioridad, lo que implica un gradual e ininterrumpido reordenamiento de los modelos y estrategias pedagógicas, así como el empleo novedosos materiales y herramientas educativas.

En estas modificaciones que se están introduciendo paulatinamente en el sistema de Educación Universitario de Ecuador, los sistemas informáticos, tales como las computadoras, las redes, los sistemas de manejo de contenidos y los programas educativos, en fin, las TICs, juegan un papel determinante y protagónico.

Autores como Venegas y Chrobak (2004), plantean que en los últimos años la expansión de la técnica ha crecido exponencialmente, destacando a la Electrónica, la Computación, y las Telecomunicaciones, como especialidades cuyo crecimiento ha sido explosivo y las describen como disciplinas recientes con una gran aplicación que han contribuido a la modificación del entorno, las cuales han afectado todas las esferas de la vida, incluyendo la de la educación. (Benegas \& Chrobak, 2009).

\subsection{Las TICs y su relación con la Educación y la sociedad moderna}

Las implicaciones del uso las actuales tecnologías de la información y las comunicaciones en la sociedad y especialmente en la educación, han sido muy amplias, ya que educar es precisamente una forma especial de comunicación. Las posibilidades de consulta del estudiante que tiene acceso a diferentes tecnologías (la web, redes académicas, plataformas de enseñanza a distancia, sistemas organizativos digitales, buscadores, etc), se potencian de manera casi ilimitada y sus tiempos de búsqueda pueden reducirse considerablemente. 
Rev. SINAPSIS, Vol. 6, Nº 1, Junio 2015

A través de las TICs, la ciencia llega a todos, de forma que en el presente no se trata solo de conservar la información, sino de producirla, organizarla y dosificarla, no para retenerla sino para diseminarla a un sinnúmero de usuarios con características y necesidades de información diferentes. (Sánchez, 2003)

Uno de los retos básicos de la educación actual es preparar a las personas para ser capaces de participar plenamente en una sociedad plagada de información en la que el conocimiento es fuente crítica de desarrollo social y económico. (Cornella, 1999), en dicha sociedad la colaboración productiva es pieza clave del conjunto de redes de organizaciones interactivas abiertas al cambio incesante, por ello, la educación actual requiere la transformación de los mecanismos de transmisión del conocimiento, y las aplicaciones educativas programadas en computadoras son algunas de las herramientas que están posibilitando modificar este proceso. (Brunner, 2002).

\subsection{Los mapas conceptuales}

La Psicología educativa ha generado estrategias de aprendizaje para que los estudiantes se vuelvan aprendices estratégicos y con ello mejoren, conscientemente, sus prerrequisitos de estudio, un ejemplo claro de estos procedimientos se denomina "Mapa Conceptual", en el cual el estudiante debe identificar los conceptos básicos, relacionarlos y generar proposiciones. (Ausubel, Novak, \& Hainesian, 1989)

Los Mapas conceptuales constituyen una de las herramientas más utilizadas en la gestión del aprendizaje, por la posibilidad que estos ofrecen de personalizar el aprendizaje, compartir conocimiento, y para aprender a aprender. Al mismo tiempo se desarrollan a gran velocidad múltiples iniciativas o estándares que permiten compatibilizar los contenidos desarrollados en diferentes plataformas y entornos educativos. (Iriarte, Duch, Martín, Peco, \& Pérez, 2002)

Ausubel, et al, en 1978, formularon la teoría del aprendizaje significativo, que ha resultado ser un gran aporte para el perfeccionamiento de la educación. Un aprendizaje se dice significativo cuando una nueva información (concepto, idea, proposición) adquiere significados para el aprendiz a través de una especie de anclaje en aspectos relevantes de la estructura cognitiva preexistente del individuo.

Basándose en aprendizaje como procesamiento de información y más específicamente en la línea de Ausubel del aprendizaje significativo, es que Novak introduce los mapas conceptuales 
Rev. SINAPSIS, Vol. 6, Nº 1, Junio 2015

como una respuesta al aprendizaje significativo, dentro del marco de un programa denominado “Aprender a Aprender”. (Ausubel, Novak, \& Hainesian, 1978)

Se trata de una propuesta metodológica de carácter abierto y por tanto, lo importante es la revisión crítica y la adaptación a las necesidades curriculares de cada profesor. Como ya se sabe, no todas las experiencias didácticas tienen los mismos resultados en los distintos grupos y niveles.

Las carreras que se estudian en la ULEAM-Chone, y más específicamente, la carrera Ingeniero en Sistemas Informáticos, no constituyen una excepción de toda esta revolución que está experimentando la educación moderna. Este trabajo se ha realizado a partir de un problema detectado en la asignatura "Redes de Computadoras", y basándose lo anteriormente mencionado.

\subsection{Situación problémica}

La enseñanza de algunas asignaturas en general y de la materia "Redes de Computadoras" en particular, específicamente en la carrera Ingeniería en Sistemas Informáticos que se estudia en la Universidad Laica Eloy Alfaro, Campus Chone, se enfrenta a algunos problemas, relacionados con sus propias características:

- Las actividades docentes durante la enseñanza de la materia antes mencionada, y sobre todo, las prácticas, exigen de laboratorios correctamente equipados y modernas instalaciones que se hacen obsoletas con mucha rapidez, lo cual implica el uso de una apreciable cantidad de recursos financieros y materiales, que no están siempre disponibles en los centros de enseñanza, por ejemplo, no siempre se cuenta con un router avanzado, un switch de capa III, o simplemente, una red informática actualizada con los estándares modernos para que estudiantes y profesores realicen sus prácticas y actividades docentes.

- La asignatura trata gran cantidad de contenidos que en no pocas ocasiones resultan ser abstractos de compleja demostración teórico - práctica, los cuales frecuentemente, presentan dificultades para ser adecuadamente comprendidos por parte de los alumnos.

- La asignatura posee gran cantidad de contenidos teóricos, lo cual implica un mayor esfuerzo por parte de sus estudiantes durante su autopreparación. 
Rev. SINAPSIS, Vol. 6, Nº 1, Junio 2015

- A lo anteriormente mencionado, es preciso añadir que, tanto en las extensión principal de la ULEAM-Chone, como en las sub extensiones, el proceso docente actual se caracteriza por tener un marcado carácter semipresencial, con marcadas tendencias constructivistas, donde la virtualización posee un destacado papel.

Los hechos anteriores dificultan el alcance de ciertas habilidades y disminuyen la calidad de la docencia, pues, no existen los laboratorios y condiciones requeridas para el normal cumplimiento de los objetivos de la asignatura, no se cuenta con el equipamiento necesario para ser empleado con fines docentes. Para tratar de suplir esas carencias, se realizaron las siguientes preguntas científicas:

¿Se puede crear una herramienta que aprovechando las actuales tecnologías de la información y las comunicaciones, contribuya a elevar la calidad del proceso docente y por consiguiente, el aprendizaje de los estudiantes, en la asignatura "Redes de Computadoras de la carrera "Ingeniería en Sistemas Informáticos", basada en una modalidad educativa semipresencial y constructivista?

¿Se puede organizar o representar el conocimiento o los contenidos de alguna forma general que permita un fácil acceso a recursos virtuales que ayuden a suplir las carencias señaladas?

\subsection{Problema}

A partir de la situación descrita, se determinó que el problema existente consiste en la limitación o insuficiencia en la adquisición de habilidades por parte de los estudiantes en la asignatura Redes de Computadoras, de la carrera de Ingeniería en Sistemas Informáticos de la Universidad Laica Eloy Alfaro, Campus Chone, ocasionada principalmente, por la falta de actividades prácticas debido a la escasez de equipos y dispositivos de redes, trazándose a partir de aquí, como objetivo de esta investigación el siguiente:

\subsection{Objetivo}

Presentar una propuesta organizativa para la asignatura Redes de Computadoras, que facilite el acceso a sus contenidos y brinde recursos virtuales de apoyo al aprendizaje en entornos educativos a distancia, mediante la organización de sus contenidos basado en forma de un mapa conceptual multimedios. 
Rev. SINAPSIS, Vol. 6, Nº 1, Junio 2015

\section{Materiales y métodos}

La investigación contó con varias etapas, la primera consistió en el diagnóstico y confirmación del problema científico, para ello se realizaron tanto entrevistas a profesores de experiencia en la asignatura, como encuestas a estudiantes que se encontraban cursando la misma. También fueron entrevistados estudiantes de la carrera que ya habían aprobado la asignatura. En esta fase también se comenzó con la elaboración del estado del arte.

\subsection{Elaboración de los recursos multimedios para el mapa conceptual}

Se lograron reunir, más de 300 recursos multimedios, como videos, animaciones, simulaciones, imágenes de procesos propios de las redes, aplicaciones (principalmente simuladores), y ejercicios asociados a éstas. La mayor parte de los recursos, fueron elaborados por parte del grupo de profesores de la asignatura, otros, se descargaron de redes públicas, teniendo en cuenta siempre su licencia de empleo. Posteriormente se diseñó el mapa conceptual y, se eligió e instaló el software a utilizar y finalmente se creó, con ayuda de éste, el mapa conceptual al cual se le integraron los recursos virtuales.

\subsection{Diseño del mapa conceptual}

Por las características del conocimiento que se deseaba representar, requería de un mapa que facilitara que, partiendo de un concepto primario e integrador (Redes de Computadoras), se pudieran derivar a otros de menor jerarquía (criterios de clasificación de las redes y organización estructural de éstas, etc.); y a su vez de estos, se obtuvieran otros más específicos (tipos de redes por su topología, tamaño, etc.), es por ello que fue elegido un mapa conceptual jerarquizado, en el que los conceptos más generales se encontraban en la parte superior del mapa, y los de menor jerarquía, en los niveles inferiores.

Al igual que la lógica del Proceso Docente Educativo, la estructura del mapa conceptual propuesto, fue diseñada, partiendo de las Redes informáticas como un ente integrador, del cual se deriva todo un conjunto de aspectos y conceptos secundarios. En todo momento se trató (y en la mayoría de los casos, se consiguió), de seguir la lógica y la estructura de la asignatura de acuerdo a la distribución de temas y unidades.

Por lo extenso que resultan los contenidos, se decidió seccionar el mapa, de manera que el conjunto de mapas resultantes, fueran lo más sencillos y comprensivos posible, para ello, se creó, un mapa inicial en el que se tratan los aspectos más generales relacionados con las redes 
Rev. SINAPSIS, Vol. 6, No 1, Junio 2015

informáticas, el cual se corresponde con los primeros contenidos del primer tema de la asignatura. (Figura 1).

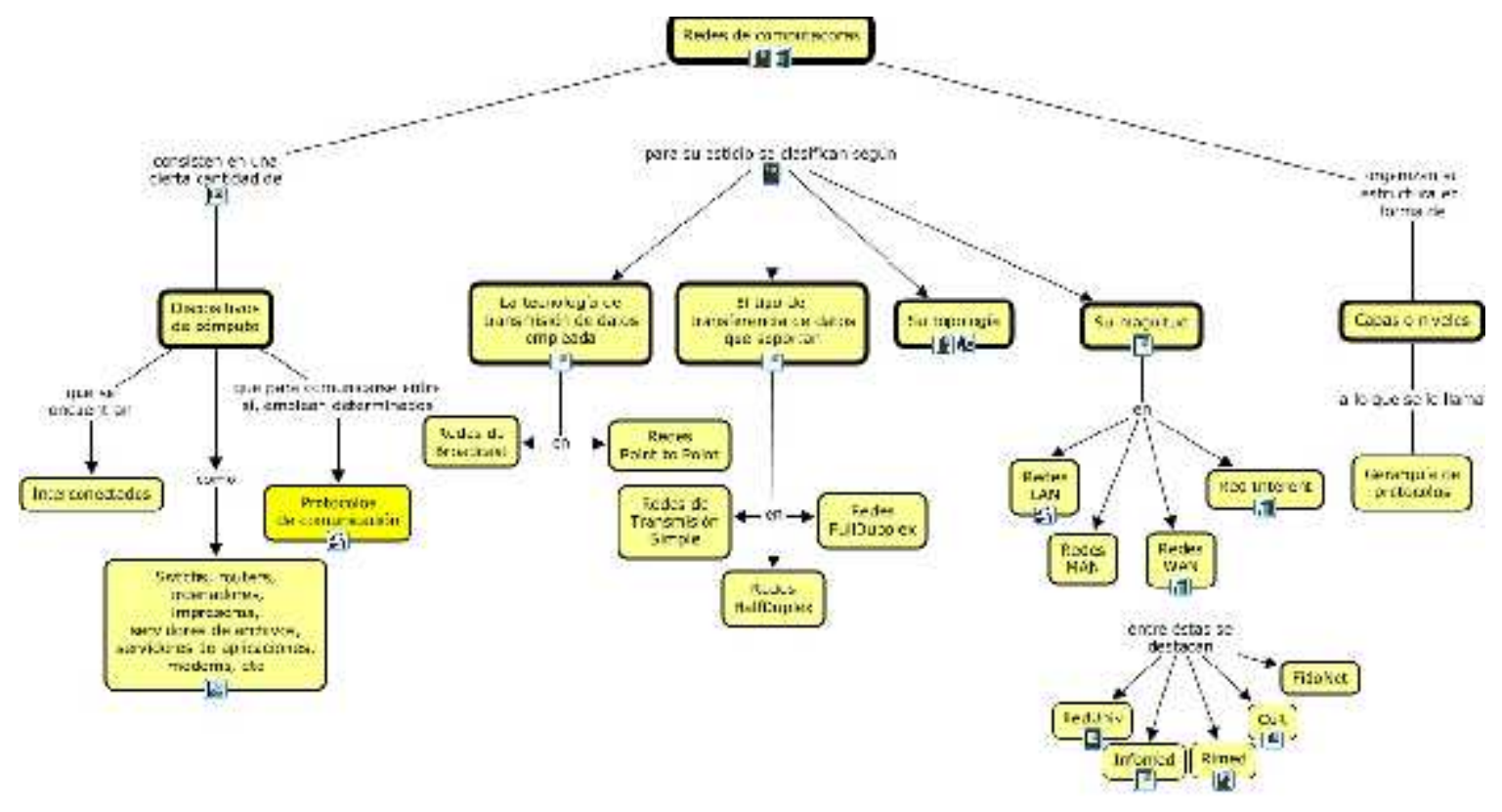

Figura 1. Mapa inicial de la asignatura "Redes de Computadoras".

De los nodos del mapa conceptual inicial, parten otros mapas con conceptos más específicos: los dedicados a los protocolos de comunicación y transmisión de datos, el destinado a la clasificación de las redes de acuerdo a su topología y el que caracteriza a las redes LAN. En la figura 1, puede notarse también que el nodo "Protocolos de comunicación" presenta un color más brillante que el de los otros que contienen ramificaciones a otros mapas conceptuales, esto se hizo para dar una idea al estudiante, de que este nodo es el que los conducirá a otros temas de la materia, o lo que es lo mismo, es el que mantiene el hilo conductor de la secuencialidad lógica del proceso de enseñanza - aprendizaje.

En la figura 2, se detalla, el mapa conceptual que representa los contenidos relacionados con los protocolos de comunicación en las redes de ordenadores. Al igual que en el mapa anterior, se parte de la representación del concepto de protocolos, su clasificación, y dentro de ésta, los protocolos actuales comprendidos dentro de cada clase, en este mapa también se abordan los contenidos de los protocolos y las redes estructuradas en capas. Desde estos mapas, existen enlaces a otros que tienen como propósito brindar información más detallada y profunda de 
Rev. SINAPSIS, Vol. 6, No 1, Junio 2015

cada uno de las protocolos existentes. Note el nodo "TCP/IP" señalado como el que conduce al mapa del siguiente tema de la asignatura (Tema II. El protocolo IP).

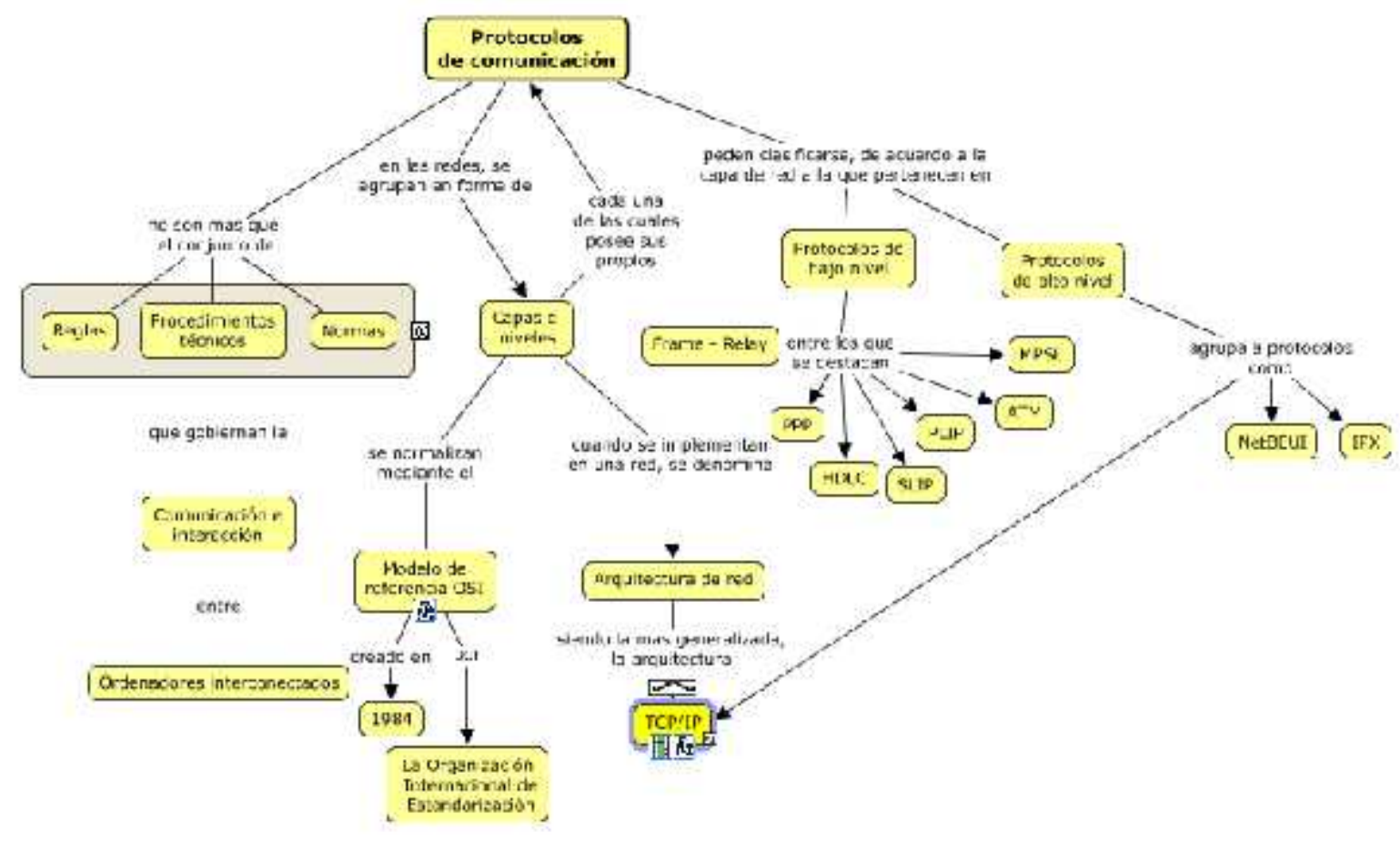

Fig. 2: Mapa conceptual donde se representan los conceptos y las relaciones básicas de los protocolos de comunicación.

Siguiendo estos criterios, se crearon los mapas del resto de los temas de la asignatura. Por lo abstracto de los contenidos, se trató de explotar al máximo el empleo de imágenes, videos, simulaciones y animaciones que ilustren los procesos propios de las redes informáticas (Figura 3).

Es importante comentar que en estos momentos, tanto el mapa conceptual, como la elaboración de los recursos multimedios, se hallan en fase de elaboración y desarrollo, por ello, en muchos nodos o conceptos, aún no existe gran cantidad de recursos multimedios asociados a ellos, pero se espera, que una vez concluido toda el proceso, cada nodo cuente con una abundante y variada cantidad de recursos multimedios.

En el sistema se profundizó bastante en los contenidos del segundo tema, el dedicado a la versión 4 del protocolo IP, pues aquí se tratan los aspectos teóricos y prácticos del protocolo más empleado a nivel mundial, no solo en la red global o la llamada Internet, sino también en intranets, redes privadas, de tipo LAN, MAN y WAN, incluso, se abordan aspectos que no están contenidos de forma explícita en los objetivos de la asignatura, como la caracterización de los protocolos de bajo nivel, los principales datos biográficos de sus creadores, detalles de La materia "Redes de Computadoras" en modalidad semipresencial. 
Rev. SINAPSIS, Vol. 6, Nº 1, Junio 2015

versiones anteriores a la actual, etc.; pues siempre se valoró la posibilidad de que ciertos estudiantes motivados, desearan profundizar en el estudio de estas materias, y desde luego, se tuvo en cuenta la eventualidad de que este material pudiera ser de interés por parte de profesores y estudiantes de otras carreras más íntimamente relacionadas con las telecomunicaciones.

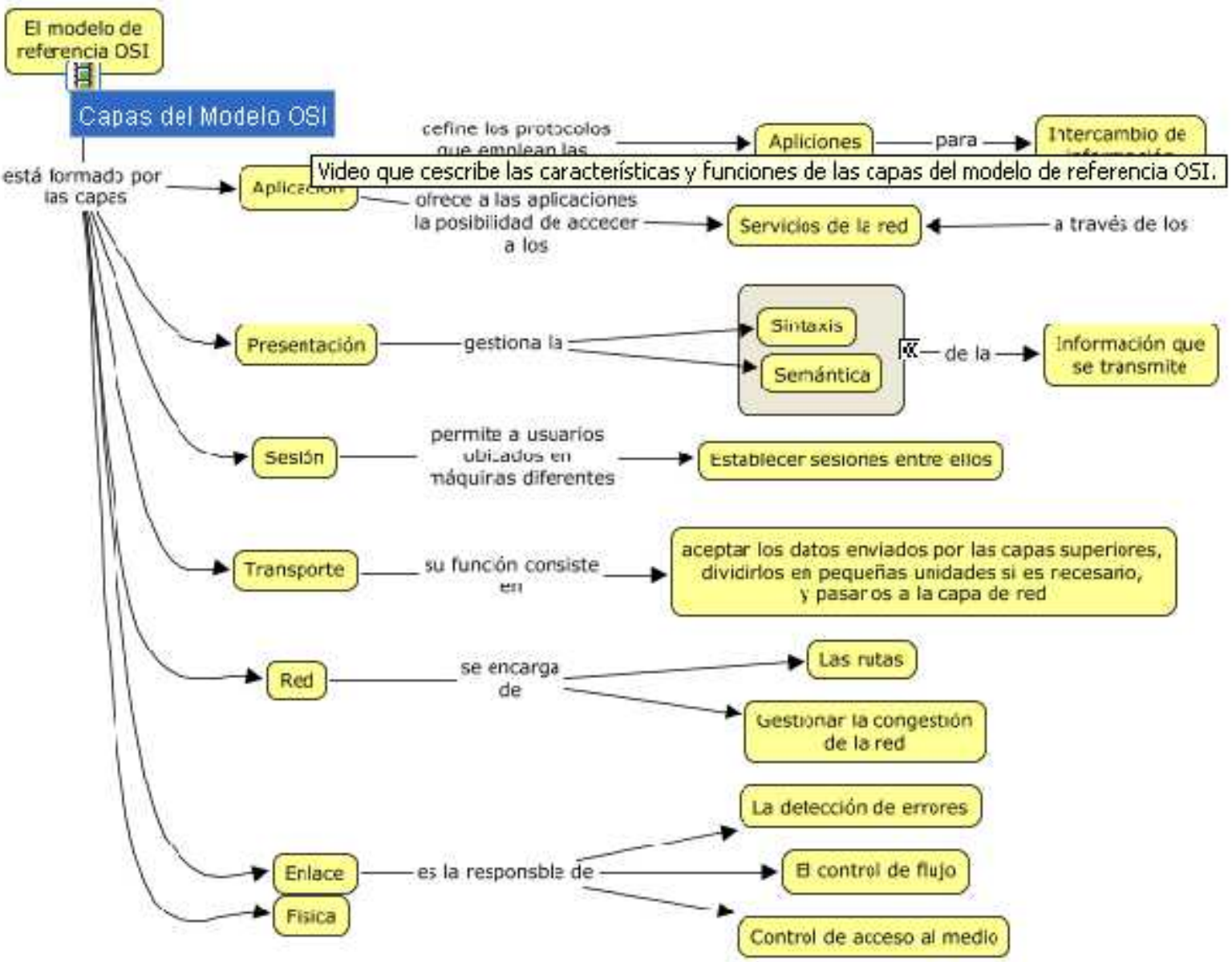

Figura 3. Mapa conceptual dedicado al modelo de referencia OSI, mostrando un video donde se explican las funciones de cada una de sus capas.

Por otra parte, este tema es el que históricamente ha presentado mayores dificultades en su comprensión y asimilación por parte de los estudiantes.

En el mapa se incluyeron el simulador de redes, encaminadores y dispositivos de red "GNS3", y el simulador de máquinas virtuales (QUEMU), mediante los cuales y con la ayuda del profesor, los estudiantes los podrán instalar en sus computadoras, o emplearlos en los laboratorios de su centro de estudios o en sus ordenadores personales, logrando que éstos se familiaricen con el funcionamiento de las redes, el diseño de rutas y el trabajo con encaminadores o enrutadores de tipo Cisco. (Figura 4). También existen animaciones de procedimientos propios de las redes y de los protocolos.

La materia "Redes de Computadoras" en modalidad semipresencial. 


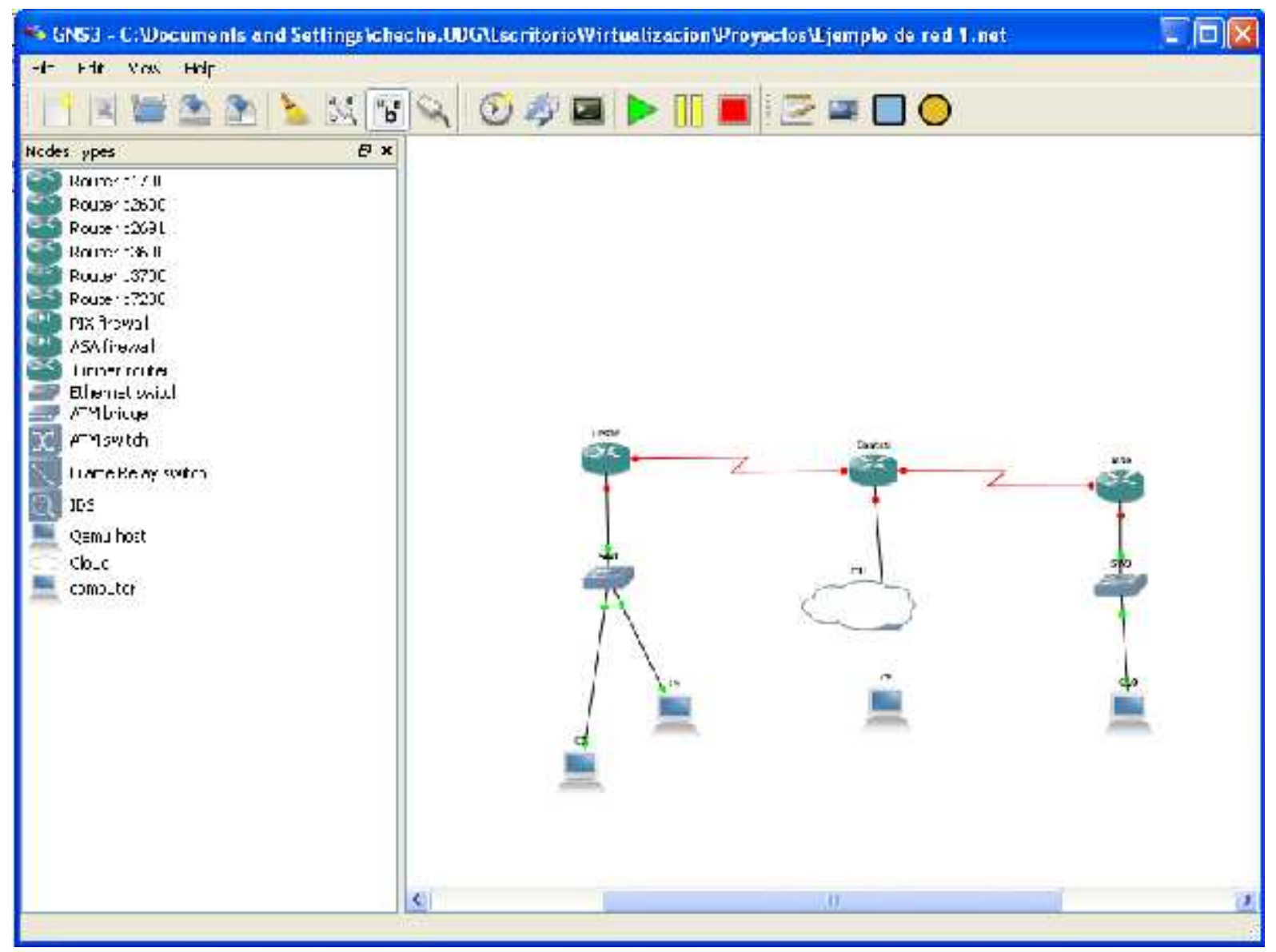

Figura 4. Simulador de redes y routers Cisco GNS3, en la figura se muestra una simulación de una red formada por tres routers.

\subsection{Elección de la herramienta adecuada para la confección del mapa}

También se hizo necesario decidir el software que se utilizaría para la confección y uso de los mapas creados, para ello, se realizaron extensas búsquedas en la redes públicas y privadas, y se detectó que existe una considerable cantidad de sistemas diseñados para el trabajo con mapas conceptuales, algunos, con propósitos comerciales, otros libres y de código abierto, y fue en éstos en los que se centró el análisis. La elección del software a emplear se basó en un conjunto de requisitos:

- Debería tratarse de un paquete basado en software libre, con código fuera abierto, con arquitectura cliente - servidor, de manera que condicionara la posibilidad de compartir el trabajo creado y posibilitara el trabajo colaborativo.

- El sistema a utilizar tendría que contar con un serio respaldo bibliográfico, científicamente fundamentado. 
Rev. SINAPSIS, Vol. 6, Nº 1, Junio 2015

- Se estableció cierta preferencia si se tratase de un software diseñado con un objetivo educativo principalmente con un elevado por ciento de utilización a escala mundial.

- Debería ser factible su empleo en la ULEAM-Chone.

El CMap, resultó ser el software elegido, el mismo cumplió con todos los requisitos que se establecieron para su elección, incluso, se pude comprobar que este software se ha convertido en un standard, pues muchas herramientas semejantes, miden, entre sus prestaciones, la compatibilidad con CMap.

El CMap posee dos módulos básicos, el CmapTools, que es la herramienta que se utiliza para crear, ver, editar o almacenar de forma local o en un servidor remoto los mapas conceptuales y el CMapServer, que es utilizado para almacenar mapas conceptuales, compartirlos, y facilitar el trabajo colaborativo.

El CMapServer se instaló en un servidor dedicado con sistema operativo Linux Fedora 18, este servidor cuenta con una dirección IP pública para garantizar el acceso y la "visibilidad" de el mapa conceptual desde las redes externas.

Los clientes, CmapTools, con ayuda de los cuales se crearon los mapas, fueron instalados en varias estaciones de trabajo con Windows 7 , Windows 8 e incluso, estaciones de trabajo basadas en software libre (Linux).

\section{Resultados}

Actualmente, como resultado de esta investigación, existe un servidor de mapas conceptuales en la ULEAM-Chone, que forma parte de la red mundial CMap, donde otras ciencias y materias podrán publicar materiales de consulta para los estudiantes.

Aunque en estos momentos solo contiene el mapa conceptual antes mencionado, si se le da la explotación adecuada, podría actuar en un futuro como un repositorio compartido de modelos de conocimientos, el cual podría contener mapas de varias asignaturas y disciplinas, formando las llamadas "sopas de conocimientos", un índice para búsquedas de otros recursos y mapas conceptuales; facilitaría además la colaboración por hilos de discusión y la colaboración sincrónica durante la edición o construcción de mapas conceptuales. En la figura 5, se destaca el servidor de mapas conceptuales de la ULEAM-Chone, insertado en la red mundial CMap.

Este servidor, suministra, a través de un pequeño servidor Web, versiones en HTML de los mapas conceptuales que contiene, lo que facilita que si no se dispone del CMapTools, es decir, 
Rev. SINAPSIS, Vol. 6, Nº 1, Junio 2015

de la herramienta cliente, sea posible acceder a los mapas existentes solamente auxiliándose de un navegador como Internet Explorer, Firefox, Netscape u otro. No obstante ser lo anterior una vía de acceso rápido a recursos y mapas en un servidor CMap, la manera óptima de explorar o consultar un mapa conceptual creado es mediante la herramienta cliente, diseñada para este fin (CMapTools), pues algunos recursos se omiten en la versión Web. La URL del servidor Web será, en un futuro muy cercano: http://cmap.uleam-chone.edu.ec.

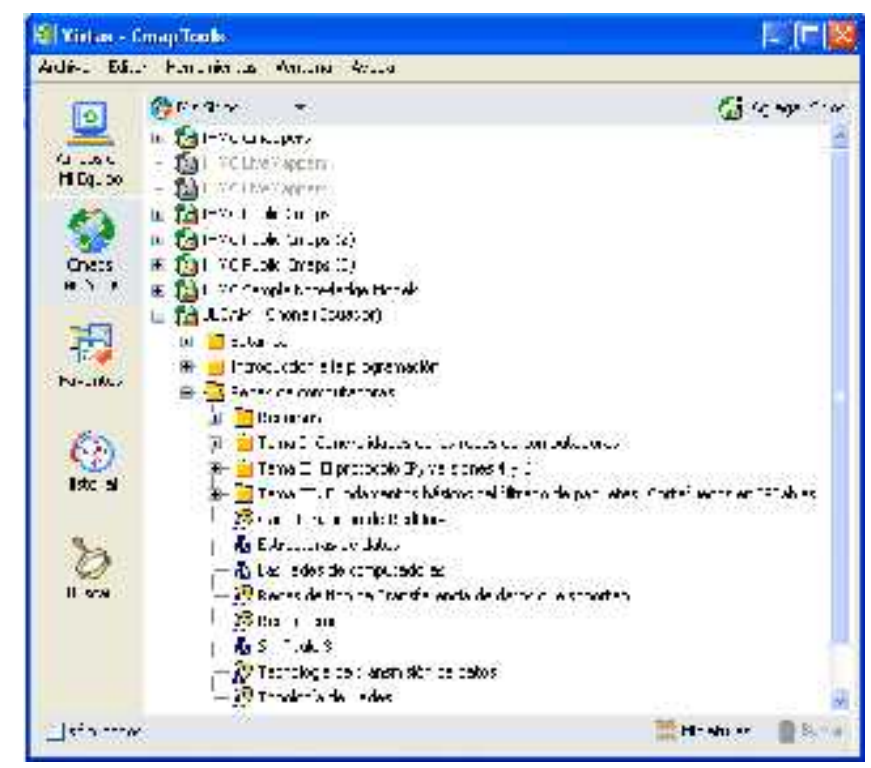

Fig. 5: Comunidad Mundial Cmap, destacando el servidor Cmap de la Universidad de Granma.

\section{Discusión}

En estos momentos, los estudiantes de carreras de perfil informático, cuentan, en el servidor CMap de la ULEAM-Chone con un Mapa Conceptual dedicado a la asignatura Redes de Computadoras, el cual constituye una efectiva herramienta para mejorar la calidad del proceso docente en un entorno a distancia o semi presencial, facilita la construcción del conocimiento, la definición de los conceptos fundamentales y la relación entre los mismos, ofreciendo un método idóneo para la autopreparación de los estudiantes y una mejor comprensión de los contenidos.

El mapa tiene asociados una notable cantidad de recursos adicionales: imágenes, animaciones, páginas web, documentos, documentos en PDF, etc, además, por la no existencia en muchos de los centros de educación superior ecuatorianos, de equipos sofisticados de red, y por las características de la asignatura, se priorizó la búsqueda y obtención de materiales que 
Rev. SINAPSIS, Vol. 6, N 1, Junio 2015

compensaran estas dificultades, como videos y simulaciones, por lo que se puede plantear que el software pone a disposición del Proceso Docente y sobre todo los estudiantes, aplicaciones de simulación para la realización de prácticas de laboratorios virtuales, lo que mejora el nivel de aprendizaje de los alumnos en la asignatura, pues con ello se facilita que éstos adquieran habilidades que en cursos en los que no se empleaban estas herramientas, no se lograban.

Es importante señalar el papel que debe jugar esta y otras herramientas similares en la generalización de las modalidades y métodos de estudios actuales, donde las actividades no presenciales deben llevar el protagonismo. En Ecuador se han hecho grandes inversiones para poder lograr este objetivo y potenciar la educación semipresencial, por ejemplo, actualmente, todas las extensiones de la ULEAM se encuentran conectadas a la red Internet; el desarrollo de todo este andamiaje a nivel provincial y cantonal, potenciará considerablemente el uso de plataformas, herramientas y aplicaciones que faciliten estas nuevas modalidades de la educación, tales como el CMapTools.

El servidor CMap de la ULEAM-Chone, facilitará las interacciones entre estudiantes y profesores, y no solo entre los pertenecientes al campus, sino más allá, pues el sistema es visible también desde la sede central, las extensiones universitarias, o incluso, desde cualquier ordenador que tenga acceso a la red global, condición muy favorable para mejorar la calidad de la docencia.

En la ULEAM-Chone, los profesores de la asignatura "Redes de Computadoras" que dirigen el proceso docente, han implantado a modo experimental, el uso y empleo del mapa conceptual que se está creando, y con ello, el uso de la aplicación CMAP por parte de los profesores que imparten la docencia y estudiantes que cursan la carrera esta nueva modalidad de estudio.

Tampoco se puede excluir de este informe, el impacto que esta herramienta ejercerá en el resto de las signaturas de la carrera y el año, principalmente a través de la vinculación horizontal y vertical de esta herramienta con otras asignaturas de ésta.

\section{Conclusiones}

- Se presenta una propuesta organizativa para la asignatura Redes de Computadoras que facilita el acceso a sus contenidos y brinda recursos virtuales de apoyo al aprendizaje en entornos educativos semipresenciales. 
Rev. SINAPSIS, Vol. 6, No 1, Junio 2015

- Se propone el empleo de un simulador de dispositivos y redes, para la realización de prácticas de laboratorios virtuales relacionadas con los encaminamientos, y la configuración de enrutadores Cisco, para las dos versiones del protocolo IP empleadas actualmente.

- Esta investigación aporta un servidor de mapas conceptuales en la ULEAM-Chone, en el que cualquier profesor, investigador, puede representar el contenido de las materias que imparte. A éste, se puede acceder desde cualquier computadora conectada a la red Internet, lo que propicia el trabajo colaborativo durante la construcción de mapas conceptuales y la posibilidad de compartir el conocimiento creado.

- La propuesta organiza los contenidos a través de mapas conceptuales que establecen asociaciones entre sus diferentes conceptos, a los que se asocian recursos de media de todo tipo: páginas web, imágenes y esquemas de estructuras de redes, informaciones, simulaciones y animaciones que auxilien el proceso de enseñanza.

\section{Bibliography}

1. Ausubel, D., Novak, J., \& Hainesian, H. (1978). Educatinal psychology: a cognitive view. New York: Holt, Rinehart and Winston. : México Trillas.

2. Ausubel, D., Novak, J. D., \& Hainesian, H. (1989). Psicología Educativa: Mexico, Trillas.

3. Benegas, M. L., \& Chrobak, R. (2009). HERRAMIENTAS COMPUTACIONALES Y EL APRENDIZAJE SIGNIFICATIVO. Paper presented at the First Int. Conference on Concept Mapping. http://cmc.ihmc.us/papers/cmc2004-035.pdf

4. Brunner, J. (2002). Desarrollo Cognitivo y Educación: Madrid, Morata.

5. Cornella, A. (1999). En la sociedad del conocimiento, la riqueza está en las ideas., 2004, from http://www.infonomics.net/cornella/afundesco.pdf

6. Iriarte, L., Duch, M., Martín, D., Peco, P., \& Pérez, C. (2002, Octubre 20-22, 2004). Mapas Conceptuales y Objetos de Aprendizaje. Paper presented at the I Simposio Pluridisciplinar sobre Diseño, Evaluación y Descripción de Contenidos Educativos Reutilizables, Guadalajara.

7. Sánchez, I. R. A. (2003). La educación a distancia. ACIMED. . ACIMED, 11(1), 3-4.

8. Torres, J., Morocho, M., \& Germán, J. (2010). La educación superior a distancia: Miradas diversas desde Iberoamérica. La educación virtual en Ecuador Madrid 28034. España: José Pardo \& Claudio Rama, 2010 Paseo de la Habana 9-11. . 